\title{
Effect of glucagon-like peptide-1 analogue liraglutide on primary cultures of rat hepatocytes isolated from lean and steatotic livers
}

\author{
Josef Fontana ${ }^{1}$, Otto Kučera ${ }^{2}$, Michal Anděl ${ }^{1}$ and Zuzana Červinková ${ }^{2}$ \\ ${ }^{1}$ Centre for Research on Diabetes, Metabolism and Nutrition, Third Faculty of Medicine, Charles University, Prague, Czech \\ Republic \\ ${ }^{2}$ Department of Physiology, Faculty of Medicine in Hradec Králové, Charles University, Hradec Králové, Czech Republic
}

\begin{abstract}
Non-alcoholic fatty liver disease and its complications are frequent causes of liver-related morbidity and mortality. Incretin glucagon-like peptide-1 (GLP-1) affects liver functions and metabolism. Although GLP-1 analogues are widely used in clinical practice, information regarding their potential toxic effect on hepatocytes in vitro is missing. Therefore, we evaluated the effect of GLP-1 analogue liraglutide on activity of caspases $3 / 7$, cell viability and oxidative stress in primary cultures of hepatocytes. Primary cultures isolated from male Wistar rats fed a standard (ST1-group, 10\% energy from fat) or a high-fat diet (HF-group, 71\% fat) for 10 weeks were incubated with liraglutide (0.1-1000 nmol/l) for $24 \mathrm{~h}$. Activities of caspases 3/7 and cellular dehydrogenases (WST-1), lactate dehydrogenase $(\mathrm{LDH})$ leakage and oxidative stress (malondialdehyde concentration and DCFDA assay) were evaluated. HF-groups vs. ST1-groups showed higher caspases activity, LDH leakage and MDA production $(p<0.001)$ and lower cellular dehydrogenases activity $(p<0.01)$. Liraglutide induced a dose-dependent decrease of caspases activity in both groups, reduction of oxidative stress in HFanimals and exerted no negative effects on other parameters. In conclusion, GLP-1 analogue liraglutide decreased activity of caspases 3/7, reduced ROS production and didn't exhibit negative effects on cell viability and oxidative stress in primary cultures of hepatocytes isolated from lean and steatotic livers.
\end{abstract}

Key words: GLP-1 — Liraglutide - Hepatocytes - Cell viability - ROS

\begin{abstract}
Abbreviations: DCFDA, dichlorodihydrofluorescein diacetate; DPP4, dipeptidyl peptidase 4; ER, endoplasmic reticulum; Ex4, exenatide; FA, fatty acids; GLP-1, glucagon-like peptide-1; HFGD, highfat gelled diet; LAP, laparotomy; LEAN, liraglutide efficacy and action in non-alcoholic steatohepatitis clinical trial; LIRA, liraglutide; NAFLD, non-alcoholic fatty liver disease; NASH, non-alcoholic steatohepatitis; SIRT1, silent mating type information regulation 2 homolog 1; TAG, triacylglycerol; TBARS, thiobarbituric acid-reactive substances; TGF- $\beta 1$, transforming growth factor $\beta 1$.
\end{abstract}

\section{Introduction}

Glucagon-like peptide-1 (GLP-1), along with gastric inhibitory polypeptide (GIP, also known as the glucose-dependent insulinotropic peptide), belong to a group of peptide hormones referred as incretins. These hormones are produced in response to the presence of chymus in gastrointestinal tract,

Correspondence to: Josef Fontana, Centre for Research on Diabetes, Metabolism and Nutrition, Third Faculty of Medicine, Charles University, Ruska 87, 10000 Prague 10, Czech Republic

E-mail: josef.fontana@lf3.cuni.cz
GLP-1 predominantly in endocrine L-cells of human ileum and colon. GLP-1 occurs as two active molecules: GLP-1(736) amide and GLP-1(7-37) in blood plasma (Eissele et al. 1992; Baggio and Drucker 2007; Holst 2007). Their biological half-life in the bloodstream is very short (1-2 min) due to a cleavage catalyzed by a degrading enzymes dipeptidyl peptidase 4 (DPP4) and neutral endopeptidases (Vilsboll et al. 2003). Molecules of active GLP-1 have several important functions in the human body: e.g. stimulation of postprandial insulin release from pancreatic beta cells, suppression of gastrointestinal tract motility and appetite or modulation of metabolic processes in tissues (Nauck et al. 1986; Baggio 
and Drucker 2007). Actions of GLP-1 can be mimicked by its analogues that have a longer half-life compared to original hormone molecule. There are several GLP-1 analogues available, e.g. exenatide (Ex4) and liraglutide. Liraglutide is a GLP-1 analogue with $97 \%$ amino acid sequence homology to native human GLP-1. It contains a fatty acid side-chain that enables its bound to plasma protein albumin resulting in prolongation of its half-life to $13 \mathrm{~h}$. This analogue is routinely used in treatment of patients with type 2 diabetes mellitus (Agersø et al. 2002; Russel-Jones and Gough 2012).

Excessive accumulation of triacylglycerols (TAG) in the liver is termed as fatty liver disease. Non-alcoholic fatty liver disease (NAFLD) is one of the most frequent liver diseases in western countries, affecting $20-30 \%$ of adult population. In its initial stages, NAFLD is characterized by an accumulation of ectopic fat in the liver. NAFLD is histologically defined by the presence of liver steatosis exceeding $5 \%$ of hepatocytes, regardless of whether it is macrovesicular, mixed or microvesicular (Kleiner et al. 2005; Kučera and Červinková 2014). $10-25 \%$ of patients with NAFLD can develop more severe form termed as non-alcoholic steatohepatitis (NASH). NASH development is characterized by several processes: immune cells recruitment, endoplasmic reticulum stress, mitochondrial dysfunction, oxidative stress and defective autophagy, resulting in hepatocyte ballooning, apoptosis and activation of hepatic stellate cells (Tsuchida and Friedman 2017; Gonzalez-Rodriguez et al. 2018). Their subsequent differentiation to myofibroblasts producing collagen I promotes development of liver fibrosis (Mehal et al. 2011; Valdecantos et al. 2018). 10-15\% of patients with NASH can develop hepatocellular carcinoma. Etiopathogenesis of NAFLD and NASH is closely linked to insulin resistance (liver manifestation of the metabolic syndrome), lipotoxicity, oxidative stress and apoptosis (Ruhl and Everhart 2004; Kim and Younossi 2008; Vanni et al. 2010). Scheme of the possible progression of NAFLD is depicted in Fig. 1. Nowadays, no widely established and highly effective treatment option for this complex pathological condition exists which leads to an intensive search for new therapeutic approach (Ratziu et al. 2015).

GLP-1 and its analogues led in in vitro and in vivo studies of several experimental animal models to modulation of liver lipid metabolism and to decrease in hepatic lipid content (Ding et al. 2006; Sharma et al. 2011; Svegliati-Baroni et al. 2011; Lee et al. 2012a; Trevaskis et al. 2012) showing its beneficial effect on liver metabolism under NAFLD conditions. Results of LEAN clinical trial (Liraglutide Efficacy and Action in Nonalcoholic steatohepatitis; Clinicaltrials.gov\#NCT01237119) showed that 48 weeks of treatment with liraglutide (once-daily $1.8 \mathrm{mg}$ s.c.) led to an improvement of histological results of NASH (Armstrong et al. 2013, 2016a). This result was accompanied by decreased liver steatosis and ballooning of hepatocytes. No statistically significant difference in Kleiner fibrosis stage was observed, however, patients treated with liraglutide had lower worsening of histological results of fibrosis when compared to placebo group ( 8 of 22 patients in placebo group showed its worsening vs. 2 of 23 patients in liraglutide group (Armstrong et al. 2016a). In a sub-study involving 14 patients of the LEAN study, Armstrong et al. described improvement of liver lipid and glucose metabolism reducing metabolic dysfunction in NASH after 12 weeks of liraglutide treatment (Armstrong et al. 2016b). These results make liraglutide more attractive for therapy of NAFLD and NASH.

Although GLP-1 analogues are widely used in clinical practice for treatment of type 2 diabetes mellitus, data about their potential toxic effect on hepatocytes in in vitro conditions are missing in literature, especially for liraglutide.

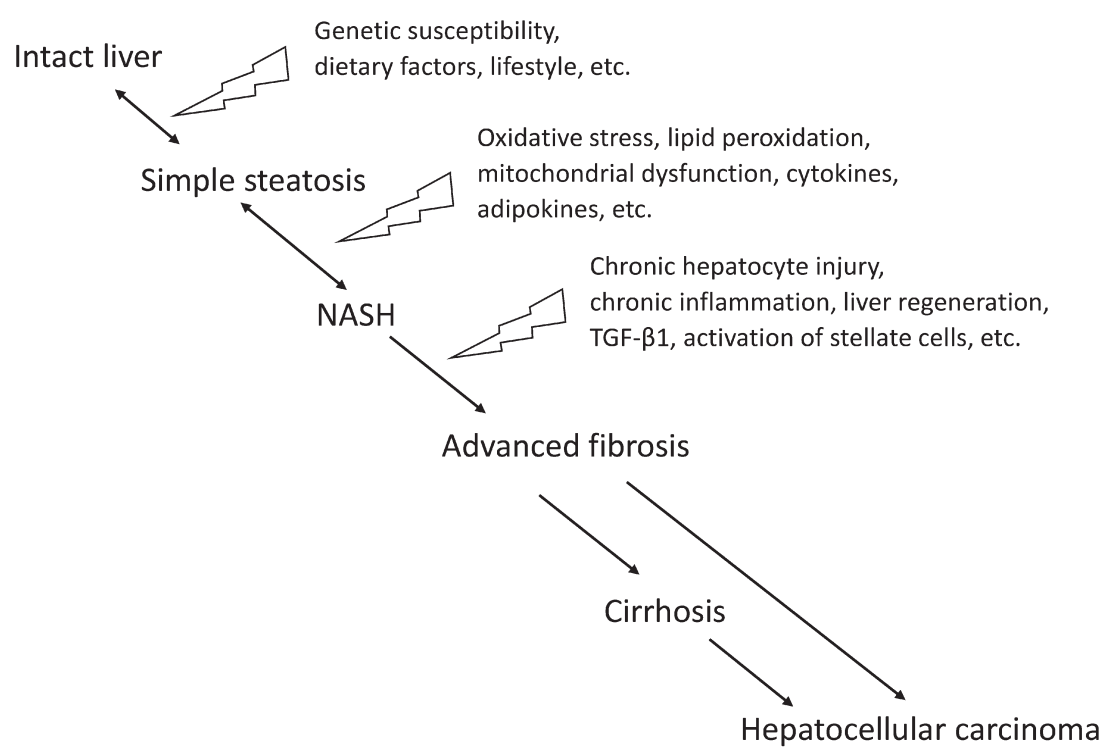

Figure 1. Scheme of the possible progression of non-alcoholic fatty liver disease. TGF- $\beta 1$, transforming growth factor $\beta 1$; NASH, nonalcoholic steatohepatitis. (Adopted from Kučera and Červinková 2014). 
Therefore, in our present work, we evaluated an effect of liraglutide on activity of caspases $3 / 7$, cell viability and oxidative stress parameters in primary cultures of hepatocytes isolated from rats fed a standard or a high-fat diet.

\section{Materials and Methods}

\section{Chemicals}

Liraglutide was purchased from Bachem AG (Bubendorf, Switzerland). William's E medium without phenol red, penicillin, streptomycin, fetal bovine serum and glutamine were supplied by BioChrom GmbH (Germany). Collagenase (from Clostridium histolyticum, Serva, Germany), insulin (Actrapid, Hoechst, Germany), glucagon (Novo Nordisk, Denmark), prednisolone (Merck, Germany), kit for lactate dehydrogenase (DiaSys, Germany), Cell Proliferation Reagent WST-1 (Roche, Germany), DCFDA (Life Technologies, Carlsbad, California, USA) and Caspase Glo 3/7 kit (Promega, Madison, Wisconsin, USA) were obtained from suppliers mentioned in the brackets. All other chemicals were of analytical grade and purchased from Sigma-Aldrich (St. Louis, Missouri, USA).

\section{Animals and experimental design}

Male Wistar rats (Biotest, Konarovice, Czech Republic) with initial body weight $235 \pm 15 \mathrm{~g}$, age 8 weeks were used throughout the study. The animals were housed at $23 \pm 1^{\circ} \mathrm{C}$, $55 \pm 10 \%$ relative humidity, and air exchange $12-14$ times/h, 12-h light/dark cycles $(6: 00 \mathrm{~h}$ to $18: 00 \mathrm{~h})$ and has had a free access to tap water and different diets as described below. All animals received care according to the guidelines set out by the Animal-Welfare Body of the Faculty of Medicine in Hradec Králové, Charles University in Prague, Czech Republic and the committee approved our experiment. All planned experiments were in agreement with law No. 246/1992 (for protection of animals against cruelty), notice No. 419/2012 (the protection of animals for experimental purposes) and Council Directive 86/609/ECC (on the approximation of laws, regulations and administrative provisions of the Member States regarding the protection of animals used for experimental and other scientific purposes).

The animals were fed ad libitum a standard laboratory pelleted diet (ST-1, Velaz, Prague, Czech Republic; 10\% energy fat, $30 \%$ energy proteins, $60 \%$ energy saccharides ST1-group) or high-fat gelled diet (HFGD; 71\% energy fat, $18 \%$ energy proteins, $11 \%$ energy saccharides - HF-group; described by Lieber et al. 2004 and Kučera et al. 2011) for 10 weeks. Supplements for HFGD diet were purchased from MP Biomedicals (Solon, OH, USA). Food and water intakes and mean body weight gain were monitored 3 times a week.

\section{Hepatocyte preparation, cultivation and treatment}

Hepatocytes were isolated from animals under ether anaesthesia by two-step collagenase perfusion as described previously (Berry et al. 1991). The body weight at time of isolation was $390 \pm 12 \mathrm{~g}$ for ST- 1 and $405 \pm 14 \mathrm{~g}$ for HFGD. The cell viability of freshly isolated hepatocytes was determined with a trypan blue exclusion test - for all isolations, it was higher than $90 \%$. Cell density was counted using a Cellometer (Nexcelom Bioscience, Lawrence, Massachusetts). Subsequently, isolated hepatocytes were suspended in William's E medium enriched with $6 \%$ fetal bovine serum, glutamine $(2 \mathrm{mmol} / \mathrm{l})$, penicillin $(100 \mathrm{IU} / \mathrm{ml})$, streptomycin $(10 \mathrm{mg} /$ $\mathrm{ml})$, insulin $(0.08 \mathrm{IU} / \mathrm{ml})$, prednisolone $(0.5 \mu \mathrm{g} / \mathrm{ml})$, glucagon $(0.008 \mu \mathrm{g} / \mathrm{ml})$ and allowed to attach on collagen-coated cultivating 6-well (at a density of $1 \times 10^{6}$ cells/well), 24-well (density of $3 \times 10^{5}$ cells/well) and 96-well (density of $3 \times 10^{4}$ cells/well) NUNC plates (Thermo Scientific, Waltham, Mass.) in a gassed atmosphere $\left(5 \% \mathrm{CO}_{2}\right)$ at $37^{\circ} \mathrm{C}$ for $2 \mathrm{~h}$. After the establishment of monolayers, the medium was removed and replaced with a fresh medium containing liraglutide with concentrations ranging from 0.1 to $1000 \mathrm{nmol} / \mathrm{l}$. Control hepatocytes were incubated in William's $\mathrm{E}$ medium, with no liraglutide. The treatment period lasted $24 \mathrm{~h}\left(5 \% \mathrm{CO}_{2}\right.$, $37^{\circ} \mathrm{C}$ ). After this period, the medium was collected for the biochemical assays and cells were harvested.

\section{Microscopic evaluation - phase contrast imaging}

The morphological changes of hepatocytes in culture were assessed using Olympus IX51 microscope equipped with the digital camera Olympus E-600 (Olympus Imaging Corp., Tokyo, Japan) and Quick Photo Camera 3.0 software (Promicra, Prague, Czech Republic). The objective magnification was set $20 \times$ for phase contrast imaging. No image editing was performed.

\section{Markers of hepatocyte damage and viability}

Lactate dehydrogenase (LDH) leakage test consisted of measurement of $\mathrm{LDH}$ activity in the culture medium and in the cell lysate (hepatocytes were frozen for $10 \mathrm{~min}$ at $-80^{\circ} \mathrm{C}$ and lysed in distilled water) using a commercial kit from DiaSys (Holzheim, Germany). The ratio of extracellular and total LDH was calculated.

Cell viability was assessed using the WST- 1 assay (2-(4-iodophenyl)-3-(4-nitrophenyl)-5-(2,4-disulfophenyl) -2H-tetrazolium, monosodium salt, Roche, Germany) evaluating the activity of intracellular dehydrogenases (described by Lotková et al. 2005). In the assay, the maternal tetrazolium salt WST-1 is cleaved to formazan by intracellular dehydrogenases. The higher the number of viable cell is, the higher the activity of the enzymes leading 
to the higher production of the formazan dye. The change directly correlates to the number of metabolically active cells in the culture. The medium was collected and the WST-1 reagent (diluted 1:10 in PBS; obtained from Roche, Penzberg, Germany) was added to the well-plates. Changes in absorbance of the dye solution were measured at time $0,1 \mathrm{~h}$ and at $2 \mathrm{~h}$ using a TECAN Infinite M200 spectrophotometer (Tecan Group AG, Männedorf, Switzerland) at a wavelength of $440 \mathrm{~nm}$. The difference between these values was calculated and used for statistical analysis.

\section{Activity of caspases 3/7}

Activity of executive caspases $3 / 7$ was evaluated using a Caspase-Glo 3/7 kit delivered from Promega (Madison, Wisconsin, USA). Incubated cells were loaded with Caspase Glo 3/7 reagent that induced cell lysis and provided a substrate for caspases $3 / 7$. The total luminescence at time 0,35 and 70 min was measured using TECAN Infinite M200 spectrophotometer (Tecan Group AG, Männedorf, Switzerland). For statistical analysis was used delta of total luminescences at time 0 and $70 \mathrm{~min}$.

\section{Markers of oxidative stress}

Intensity of lipid peroxidation in hepatocytes was determined by evaluating malondialdehyde (MDA) production by measuring the level of thiobarbituric acid-reactive substances (TBARS) in the medium (Ohkawa et al. 1979). In the method thiobarbituric acid (TBA) is reacted with MDA resulting in the formation of the chromogen that can be determined spectrophotometrically.

The production of reactive oxygen species (ROS) was evaluated using the fluorescence probe dichlorodihydrofluorescein diacetate (DCFDA) obtained from Life Technologies (Carlsbad, California, USA). DCFDA is a fluorogenic dye that detects activity of ROS (e.g. hydroxyl and peroxyl) in cells. After diffusion through membrane, intracellular esterases cleave off the acetate groups forming a non-fluorescent molecule that is subsequently oxidized by ROS into 2',7'-dichlorofluorescein (DCF). DCF is a highly fluorescent compound which can be detected. After the incubation, well-plates were rinsed with free culture medium and consequently loaded by DCFDA diluted in medium $(1 \mu \mathrm{mol} / \mathrm{l})$ for $30 \mathrm{~min}$ incubation at $37^{\circ} \mathrm{C}$. Then the substrate was removed and the well-plates were washed with the medium. After an additional $45 \mathrm{~min}$, the increase of fluorescence intensity was assessed in a TECAN Infinite M200 spectrophotometer (Tecan Group AG, Männedorf, Switzerland) using an excitation and emission wavelength of 485 and $535 \mathrm{~nm}$, respectively. The results were related to the amount of total protein extracted from the cells determined by the Bradford assay (Bradford 1976).

\section{Statistical analysis}

Results are expressed as the mean \pm SD. GraphPad Prism 6.01 software (La Jolla, California, USA) was used for statistical analysis. Kolmogorov-Smirnov test was used for proving the normality. Data with Gaussian distribution were analyzed using ANOVA followed by Tukey-Kramer's post hoc test for group comparison. In non-Gaussian distribution, nonparametric Kruskal-Wallis tests and Dunn's post hoc test were used. For the assessment of caspases' activity over concentrations of liraglutide we used simple linear regression, which was done by using SPSS Statistics software. Values of $p<0.05$ were considered statistically significant.

\section{Results}

\section{Phase contrast microscopy}

Morphological changes of hepatocytes are shown on representative microphotographs of primary cultures (Fig. 2). Hepatocytes isolated from HF-group animals exerted mi-

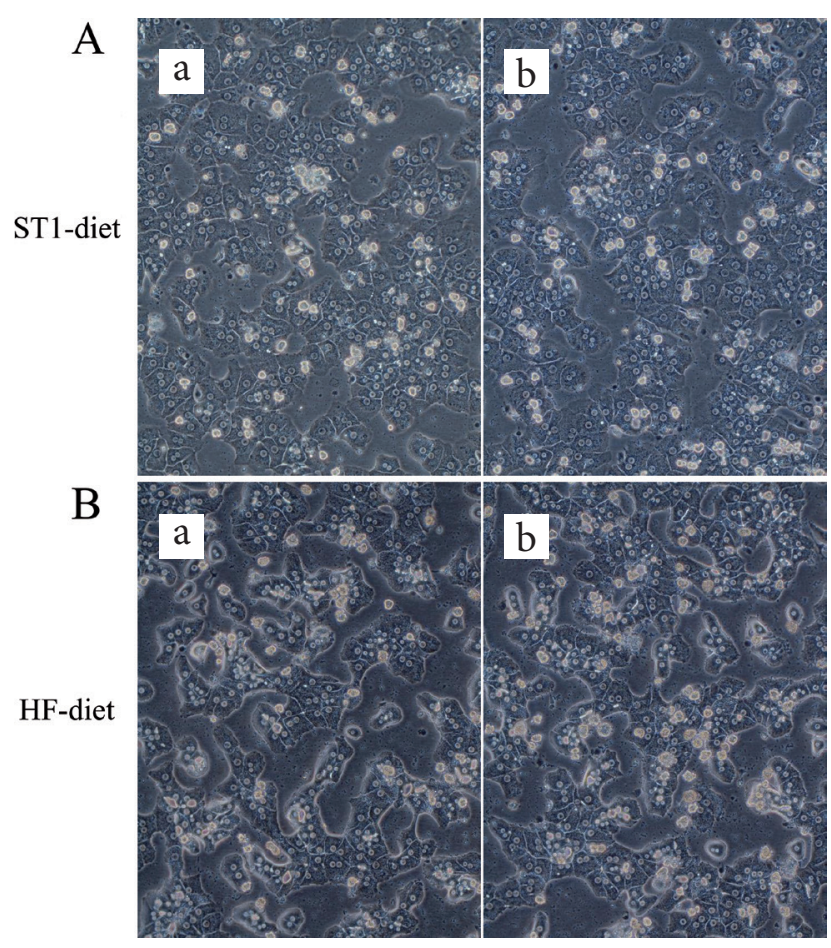

Figure 2. Morphology of primary cultures of hepatocytes after $24 \mathrm{~h}$ of incubation. Representative microphotographs of hepatocytes from rats on ST1-diet (A) and HF-diet (B). a. Control hepatocytes. b. Hepatocytes treated with LIRA $100 \mathrm{nmol} / \mathrm{l}$. Phase contrast, objective magnification $20 \times$ for all microphotographs. ST- 1 diet, the animals were fed a standard laboratory diet, HF-diet, the animals were fed a high-fat diet; LIRA, liraglutide. 
crovesicular steatosis (Fig. 2Ba) in comparison with hepatocytes isolated from lean ST1-group animals (Fig. 2Aa). Incubation with liraglutide for $24 \mathrm{~h}$ was not associated with any significant changes on morphology of cultivated hepatocytes (Figs. $2 \mathrm{Ab}$ and $\mathrm{Bb}$ - concentration of liraglutide $100 \mathrm{nmol} / \mathrm{l}$ ).

\section{Hepatocyte damage and viability}

In both assays, LDH leakage and WST-1 test, hepatocytes from HF-group showed a lower cell viability as documented by higher LDH leakage and lower activity of intracellular dehydrogenases $(p<0.001$ for all comparisons in LDH leakage; $p<0.001$ for LIRA0.1 and LIRA $1, p<0.001$ for LIRA10, LIRA 100 and LIRA1000 in WST-1 assay). Liraglutide treatment did not exert any negative effect on cell viability in both assays (Fig. 3 and Fig. 4).

\section{Activity of caspases 3/7}

Activities of caspases 3/7, as a marker of apoptosis, were higher in all HF-groups when compared to respective ST1-groups ( $p<0.001$ for all comparisons). Simple linear regression revealed linear relationship between the activity and concentration of liraglutide for ST1-groups $\left(-1521.48, \mathrm{SE}=241.1, \mathrm{R}^{2}=\right.$ $0.464)$ which is statistically significant $(p<0.001)$. We obtained similar association for HF-groups $\left(-1306.05, \mathrm{SE}=189.9, \mathrm{R}^{2}=\right.$ $0.507)$ which is also statistically significant $(p<0.001$; Fig. 5).

\section{ROS production}

Significantly higher concentrations of MDA were observed in hepatocytes isolated from animals fed a high-fat diet

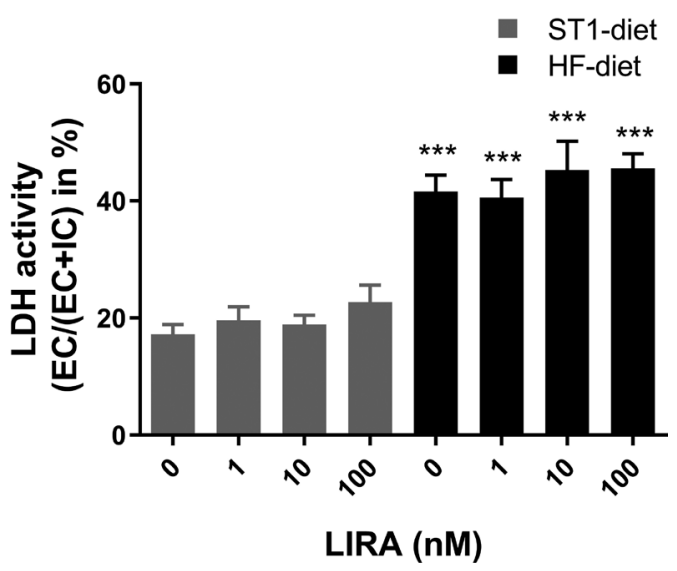

Figure 3. LDH leakage after $24 \mathrm{~h}$ of incubation with William's E me$\operatorname{dium}(0$ - controls) and with medium containing LIRA at concentration of 1,10 and $100 \mathrm{nmol} / \mathrm{l}$, respectively. Data are expressed as ratio between EC and total LDH activity (IC + EC) $\left(n=6\right.$; ${ }^{* * *} p<0.001$ $v s$. corresponding ST1-groups). EC, extracellular; IC, intracellular; LDH, lactate dehydrogenase. (For more abbreviations, see Fig. 2).

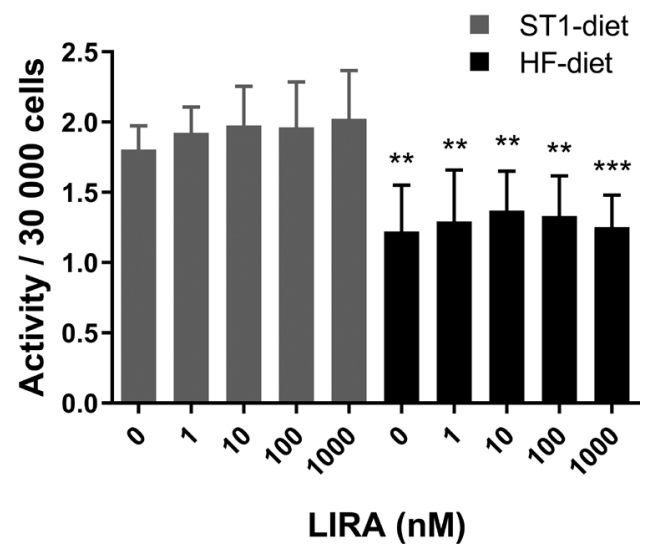

Figure 4. WST-1 assay. Activity of cellular dehydrogenases after $24 \mathrm{~h}$ of incubation with William's E medium $(0$ - controls $)$ and with medium containing LIRA at concentration of $1,10,100$ and $1000 \mathrm{nmol} / \mathrm{l}$, respectively $\left(n=8 ;{ }^{* *} p<0.01,{ }^{* * *} p<0.001 v s\right.$. corresponding ST1-groups). For abbreviations, see Fig. 2).

in comparison to respective ST1-group $(p<0.001$ for all comparisons). No effect of liraglutide on this parameter was found in any group. On the other hand, DCFDA assay revealed a reduction of ROS production in HF-group after liraglutide exposure (HF-C vs. HF-LIRA100: $p<0.05$; HF-C vs. HF-LIRA1000: $p<0.001$; Fig. 6 and Fig. 7).

\section{Discussion}

The potential of incretin based therapies in diabetology has been theoretically described for more than 20 years ago (Gutniak et al. 1992). Subsequently the basic experimental and clinical-physiological pillars of this therapy have been developed mainly by the groups around Holst (Holst 2007, 2008), Nauck (Nauck et al. 1997, 1998; Nauck 2008) and Ahren (Ahren 1998). Nowadays, there are two groups of drugs with known therapeutic potential based on modulation of the incretin system, GLP-1 analogues and DPP4 inhibitors. Both groups have proven to be effective option and have been a part of treatment of type 2 diabetes for many years now (Tuch 2016).

In the literature, there are many works studying the effect of GLP-1 analogues on metabolism of hepatocytes and liver function. Intensively studied field is especially hepatic metabolism of lipids, since several studies postulated possible beneficiary effect of incretins and related incretin-based therapies in the treatment of NAFLD/NASH condition (Lee 2012b; Samson and Bajaj 2013; Armstrong et al. 2016a). Several in vitro and in vivo animal studies assessed the effect of GLP-1 and its analogues on parameters of liver lipid metabolism - e.g. hepatic lipid content, gene expression of key enzymes and transport proteins of fatty acids (FA) and 


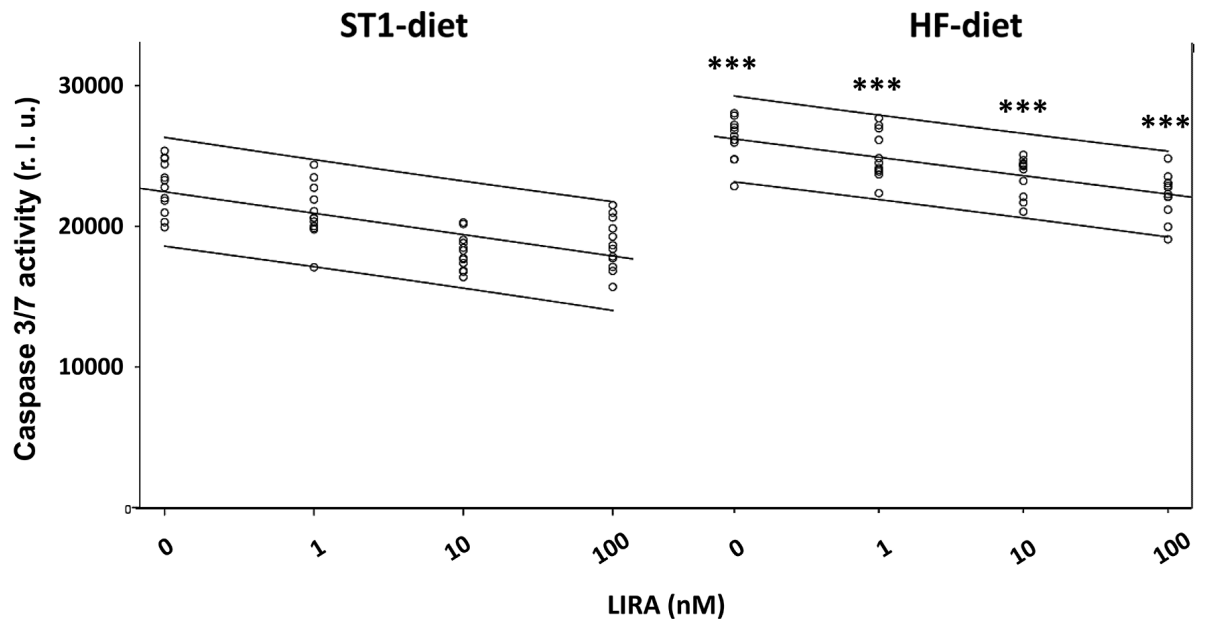

Figure 5. Activity of caspases $3 / 7$ after 24 h of incubation $(n=12$; ${ }^{* * *} p<0.001 v s$. corresponding ST1groups). Simple linear regression of caspases' activity over concentrations of LIRA for ST1-groups and HF-groups revealed linear relationship ( $p<0.001$ for both groups). r.l.u., relative light units. (For more abbreviations, see Fig. 2).
TAG metabolism etc. - concluding with promising results (Ding et al. 2006; Sharma et al. 2011; Svegliati-Baroni et al. 2011; Lee et al. 2012a; Trevaskis et al. 2012). These animal experiments were supported by works describing positive findings of incretin-based therapies on liver parameters of patients with diabetes in clinical practice (Tushuizen et al. 2006; Buse et al. 2007; Klonoff et al. 2008; Kenny et al. 2010; D'Amico 2011; Sathyanarayana et al. 2011; Cuthbertson et al. 2012; Ohki et al. 2012; Vilsbøll et al. 2012). Subsequently, LEAN clinical trial (Armstrong et al. 2013), which focused on liraglutide action in overweight patients with a histological evidence of NASH, described an improvement of histological results of NASH, decreased liver steatosis and ballooning of hepatocytes and improvement of liver lipid metabolism reducing metabolic dysfunction in NASH (Armstrong et al. 2016a, 2016b). However, in the

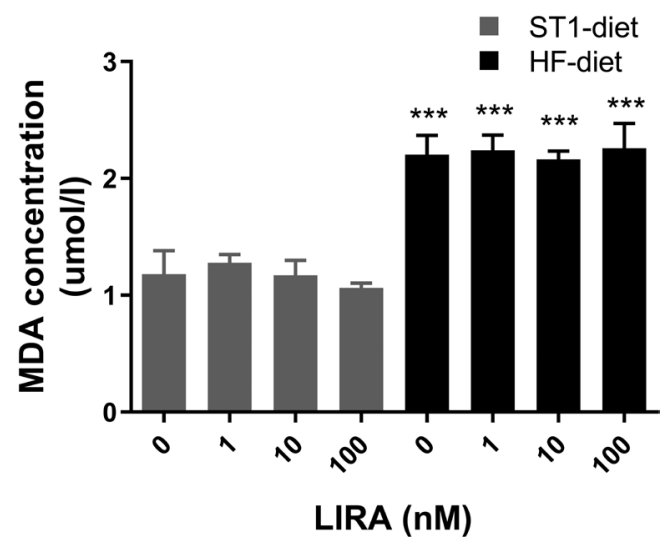

Figure 6. Concentration of MDA after $24 \mathrm{~h}$ of incubation with William's E medium ( 0 - controls) and with medium containing LIRA at concentration of 1,10 and $100 \mathrm{nmol} / \mathrm{l}$, respectively $\left(n=6\right.$; $^{* * *} p<$ $0.001 v s$. corresponding ST1-groups). MDA, malondialdehyde. (For more abbreviations, see Fig. 2). literature there is a gap in knowledge of effects of liraglutide on the hepatocyte viability and oxidative stress. This missing information we found as crucial since both parameters are modified in the NAFLD/NASH condition. In the current study we try to elucidate the effect of liraglutide on these parameters in both, normal and steatotic liver.

Excess of fatty acids (esp. saturated FA) may induce an endoplasmic reticulum (ER) stress response that can lead to an activation of signalling pathways (including caspase cascade) causing hepatocyte cell death (Zhang et al. 2011; Gentile et al. 2011). We described, that activity of caspases 3/7 was higher in hepatocytes isolated from HF-animals when compared to respective ST1-groups, which is a finding

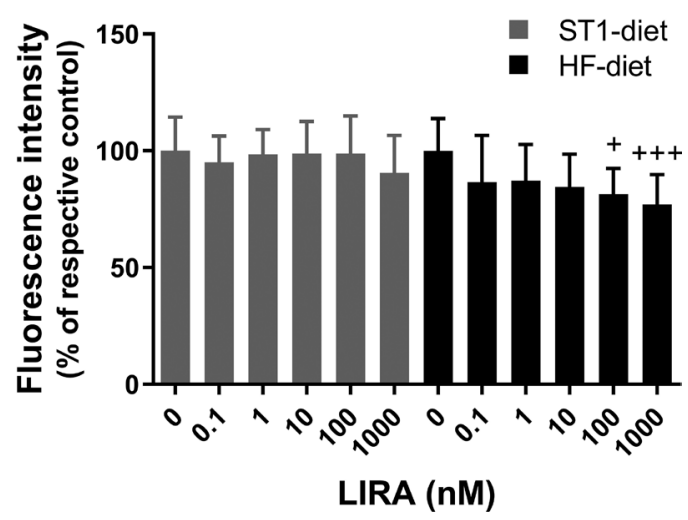

Figure 7. DCFDA assay. Production of ROS after $24 \mathrm{~h}$ of incubation with William's E medium (0 - controls) and with medium containing LIRA at concentration of $0.1,1,10,100$ and 1000 $\mathrm{nmol} / \mathrm{l}$, respectively. Data are expressed as percentage of fluorescence intensity of respective control $(n=16 ;+p<0.05,+++p<$ $0.001 v s$. HF-control group). DCFDA, dichlorodihydrofluorescein diacetate; ROS, reactive oxygen species. (For more abbreviations, see Fig. 2). 
described previously in in vitro models of NAFLD/NASH induced by cultivation of primary human hepatocytes (Sharma et al. 2011), HepG2 cells (Lee et al. 2014) and primary cultures of rat hepatocytes (Moravcová et al.2015) with different FA. Cultivation of hepatocytes from both groups in the medium with liraglutide led to a significant decrease of activity of caspases 3/7 (thus suppression of apoptosis). Based on the statistical analysis, the described effect was dosedependent. To our best knowledge, there are no previous studies describing a positive effect of liraglutide on activity of caspases $3 / 7$ in primary cultures of rat hepatocytes. In the literature, there are several studies concerning the effect of other GLP-1 analogue exenatide on caspases activity (Sharma 2011; Gezginci-Oktayoglu et al. 2011; Lee et al. 2014). Lee et al. described that Ex4 improves steatohepatitis in mice fed with a high-fat diet by increasing SIRT1 signalling (Lee et al. 2012a). Similar decline in activity of caspases as in our present work was described for primary human hepatocytes (Sharma et al. 2011) and HepG2 cells (Lee et al. 2014). A possible underlying mechanism is attenuation of ER stress (enhanced capacity to handle the unfolded protein response) via SIRT-1 dependent mechanisms leading to prevention of hepatocyte cell death via apoptosis (Sharma et al. 2011; Lee at al. 2014).

Hepatocytes from HF-animals when compared to ST1hepatocytes showed, based on the results of WST-1 assay and LDH leakage, significantly increased cell damage and lower viability. This finding for fat-laden hepatocytes has been already described in our previous experiment with the same experimental animal model (Kučera et al. 2012), or in experimental models of in vitro induction of steatosis by incubation of primary cultures of hepatocytes with different FA (Sharma et al. 2011; Moravcová et al. 2015). Liraglutide treatment did not exert any negative effect on cell viability in both assays. Sharma et al. and Aviv et al. described in in vitro conditions a positive effect of Ex4 on hepatocyte viability assessed by MTT and XTT assays that are similar to WST-1 assay used in our study (Aviv et al. 2009; Sharma et al. 2011). Our results thus support and correspond with the previous literature data that GLP- 1 analogues do not cause negative effects on hepatocyte viability.

Concerning the oxidative stress, we assessed markers evaluating two distinct segments of ROS metabolism: concentration of MDA, marker of lipid peroxidation, and DCFDA assay. MDA level was elevated for hepatocytes from HF-group when compared to respective ST1-hepatocytes. This is in good accordance with our previous results: for the same experimental model as in the present study (Kučera et al. 2012), or for primary cultures of rat hepatocytes exposed in vitro to FA (Moravcová et al. 2015). Liraglutide treatment led in our present study to a decrease in ROS production evaluated by DCFDA assay in HF-group. Reduced oxidative stress has already been described: for Ex4 in liver homoge- nates obtained for ob/ob mice (assessed by TBARS/MDA concentration; Ding et al. 2006); and for GLP-1-derived nonapeptide GLP-1(28-36)amide in a study on primary cultures of hepatocytes isolated from diet-induced obesity (DIO) mice and normal (C57bl/6J) mice or on H4IIe hepatocyte cell line (evaluated by DCFDA assay; Tomas et al. 2011).

\section{Conclusion}

In conclusion, our results suggest that GLP- 1 analogue liraglutide expresses a beneficial action in primary cultures of hepatocytes isolated from male Wistar rats fed a standard laboratory or a high-fat diet by decreasing the activity of caspases $3 / 7$ and reducing oxidative stress. No negative effects on cell viability were described. These findings can support a further research and usage of liraglutide in treatment of human liver diseases, especially NAFLD/NASH.

\section{Brief summary}

In our article, we described that glucagon-like peptide-1 analogue Liraglutide decreased activity of caspases $3 / 7$, reduced oxidative stress and did not exhibit negative effects on cell viability in primary cultures of hepatocytes isolated from male Wistar rats fed a standard laboratory or a highfat diet. These findings can support a further research and usage of Liraglutide in treatment of human liver diseases, especially NAFLD/NASH.

Acknowledgments. This work was supported by grant from Charles University in Prague PROGRES Q40/02.

Conflict of interest. The authors state that there are no conflicts of interest regarding the publication of this article.

\section{References}

Agersø H, Jensen LB, Elbrønd B, Rolan P, Zdravkovic M (2002): The pharmacokinetics, pharmacodynamics, safety and tolerability of NN2211, a new long-acting GLP-1 derivative, in healthy men. Diabetologia 45, 195-202 https://doi.org/10.1007/s00125-001-0719-Z

Ahrén B (1998): Glucagon-like peptide-1 (GLP-1): a gut hormone of potential interest in the treatment of diabetes. Bioassays 20, $642-651$

https://doi.org/10.1002/(SICI)1521-1878(199808)20:8<642::AID-BIES7>3.0.CO;2-K

Armstrong MJ, Barton D, Gaunt P, Hull D, Guo K, Stocken D, Gough SC, Tomlinson JW, Brown RM, Hübscher SG, Newsome PN; LEAN trial team (2013): Liraglutide efficacy and action in non-alcoholic steatohepatitis (LEAN): study protocol for 
a phase II multicentre, double-blinded, randomised, controlled trial. BMJ Open 3, e003995

https://doi.org/10.1136/bmjopen-2013-003995

Armstrong MJ, Gaunt P, Aithal GP, Barton D, Hull D, Parker R, Hazlehurst JM, Guo K; LEAN trial team, Abouda G, et al. (2016a): Liraglutide safety and efficacy in patients with nonalcoholic steatohepatitis (LEAN): a multicentre, double-blind, randomised, placebo-controlled phase 2 study. Lancet 387, 679-690 https://doi.org/10.1016/S0140-6736(15)00803-X

Armstrong MJ, Hull D, Guo K, Barton D, Hazlehurst JM, Gathercole LL, Nasiri M, Yu J, Gough SC, Newsome PN, Tomlinson JW (2016b): Glucagon-like peptide 1 decreases lipotoxicity in non-alcoholic steatohepatitis. J. Hepatol. 64, 399-408 https://doi.org/10.1016/j.jhep.2015.08.038

Aviv V, Meivar-Levy I, Rachmut IH, Rubinek T, Mor E, Ferber S (2009): Exendin-4 promotes liver cell proliferation and enhances the PDX-1-induced liver to pancreas transdifferentiation process. J. Biol. Chem. 284, 33509-33520 https://doi.org/10.1074/jbc.M109.017608

Baggio LL, Drucker DJ (2007): Biology of incretins: GLP-1 and GIP. Gastroenterology 132, 2131-2157 https://doi.org/10.1053/j.gastro.2007.03.054

Berry MN, Edwards AM, Barritt GJ (1991): High-yield preparation of isolated hepatocytes from rat liver. In: Isolated Hepatocytes: Preparation, Properties and Application. (Eds. Burdon RH, van Knippenberg PH), pp. 15-58, N.Y., Elsevier, New York https://doi.org/10.1016/S0075-7535(08)70023-8

Bradford MM (1976): A rapid and sensitive method for the quantitation of microgram quantities of protein utilizing the principle of protein-dye binding. Anal. Biochem. 72, 248-254 https://doi.org/10.1016/0003-2697(76)90527-3

Buse JB, Klonoff DC, Nielsen LL, Guan X, Bowlus CL, Holcombe JH, Maggs DG, Wintle ME (2007): Metabolic effects of two years of exenatide treatment on diabetes, obesity, and hepatic biomarkers in patients with type 2 diabetes: an interim analysis of data from the open-label, uncontrolled extension of three double-blind, placebo-controlled trials. Clin. Ther. 29, 139-153 https://doi.org/10.1016/j.clinthera.2007.01.015

Cuthbertson DJ, Irwin A, Gardner CJ, Daousi C, Purewal T, Furlong N, Goenka N, Thomas EL, Adams VL, Pushpakom SP, et al. (2012): Improved glycaemia correlates with liver fat reduction in obese, type 2 diabetes, patients given glucagon-like peptide-1 (GLP-1) receptor agonists. PLoS One 7, e50117 https://doi.org/10.1371/journal.pone.0050117

D'Amico E (2011): Efficacy of liraglutide in a patient with type 2 diabetes and cryptogenic cirrhosis. Acta Biomed. 82, $160-161$

Ding X, Saxena NK, Lin S, Gupta NA, Anania FA (2006): Exendin-4, a glucagon-like protein-1 receptor agonist, reverses hepatic steatosis in ob/ob mice. Hepatology 43, 173-181 https://doi.org/10.1002/hep.21006

Eissele R, Goke R, Willemer S, Harthus HP, Vermeer H, Arnold R, Goke B (1992): Glucagon-like peptide-1 cells in the gastrointestinal tract and pancreas of rat, pig and man. Eur. J. Clin. Invest. 22, 283-291

https://doi.org/10.1111/j.1365-2362.1992.tb01464.x
Gentile CL, Frye MA, Pagliassotti MJ (2011): Fatty acids and the endoplasmic reticulum in nonalcoholic fatty liver disease. Biofactors 37, 8-16

https://doi.org/10.1002/biof.135

Gezginci-Oktayoglu S, Sacan O, Yanardag R, Karatug A, Bolkent $S$ (2011): Exendin-4 improves hepatocyte injury by decreasing proliferation through blocking NGF/TrkA in diabetic mice. Peptides 32, 223-231 https://doi.org/10.1016/j.peptides.2010.10.025

Gonzalez-Rodriguez A, Valdecantos MP, Rada P, Addante A, Barahona I, Rey E, Pardo V, Ruiz L, Laiglesia LM, Moreno-Aliaga MJ, et al. (2018): Dual role of protein tyrosine phosphatase 1B in the progression and reversion of non-alcoholic steatohepatitis. Mol. Metab. 7, 132-146 https://doi.org/10.1016/j.molmet.2017.10.008

Gutniak M, Orskov C, Holst JJ, Ahrén B, Efendic S (1992): Antidiabetogenic effect of glucagon-like peptide-1 (7-36)amide in normal subjects and patients with diabetes mellitus. N. Engl. J. Med. 326, 1316-1322 https://doi.org/10.1056/NEJM199205143262003

Holst JJ (2007): The physiology of glucagon-like peptide 1. Physiol. Rev. 87, 1409-1439 https://doi.org/10.1152/physrev.00034.2006

Holst JJ (2008): Pharmacology of GLP-1 based therapies. Brit J. Diab. Vasc. Dis. 8 (Suppl. 2), S10-S18 https://doi.org/10.1177/1474651408100523

Kim CH, Younossi ZM (2008): Nonalcoholic fatty liver disease: a manifestation of the metabolic syndrome. Cleve. Clin. J. Med. 75, 721-728 https://doi.org/10.3949/ccjm.75.10.721

Kenny PR, Brady DE, Torres DM, Ragozzino L, Chalasani N, Harrison SA (2010): Exenatide in the treatment of diabetic patients with non-alcoholic steatohepatitis: a case series. Am. J. Gastroenterol. 105, 2707-2709

https://doi.org/10.1038/ajg.2010.363

Kleiner DE, Brunt EM, Van Natta M, Behling C, Contos MJ, Cummings OW, Ferrell LD, Liu YC, Torbenson MS, Unalp-Arida A (2005). Design and validation of a histological scoring system for nonalcoholic fatty liver disease. Hepatology 41, 1313-1321 https://doi.org/10.1002/hep.20701

Klonoff DC, Buse JB, Nielsen LL, Guan X, Bowlus CL, Holcombe JH, Wintle ME, Maggs DG (2008): Exenatide effects on diabetes, obesity, cardiovascular risk factors and hepatic bio markers in patients with type 2 diabetes treated for at least 3 years. Curr. Med. Res. Opin. 24, 275-286 https://doi.org/10.1185/030079907X253870

Kučera $\mathrm{O}$, Garnol T, Lotková $\mathrm{H}$, Staňková $\mathrm{P}$, Mazurová $\mathrm{Y}$, Hroch M, Bolehovská R, Roušar T, Červinková Z (2011): The effect of rat strain, diet composition and feeding period on the development of a nutritional model of non-alcoholic fatty liver disease in rats. Physiol. Res. 60, 317-328

Kučera $\mathrm{O}$, Al-Dury S, Lotková $\mathrm{H}$, Roušar $\mathrm{T}$, Rychtrmoc D, Červinková Z (2012): Steatotic rat hepatocytes in primary culture are more susceptible to the acute toxic effect of acetaminophen. Physiol. Res. 61 (Suppl. 2), S93-101

Kučera O, Červinková Z (2014): Experimental models of nonalcoholic fatty liver disease in rats. World J. Gastroenterol. 20, 8364-8376 
https://doi.org/10.3748/wjg.v20.i26.8364

Lee J, Hong SW, Chae SW, Kim DH, Choi JH, Bae JC, Park SE, Rhee EJ, Park CY, Oh KW, et al. (2012a): Exendin-4 improves steatohepatitis by increasing Sirt1 expression in high-fat dietinduced obese C57BL/6J mice. PLoS One 7, e31394 https://doi.org/10.1371/journal.pone.0031394

Lee J, Hong SW, Rhee EJ, Lee WY (2012b): GLP-1 receptor agonist and non-alcoholic fatty liver disease. Diabetes Metab. J. 36, 262-267 https://doi.org/10.4093/dmj.2012.36.4.262

Lee J, Hong SW, Park SE, Rhee EJ, Park CY, Oh KW, Park SW, Lee WY (2014): Exendin-4 attenuates endoplasmic reticulum stress through a SIRT1-dependent mechanism. Cell Stress Chaperones 19, 649-656 https://doi.org/10.1007/s12192-013-0490-3

Lieber CS, Leo MA, Mak KM, Xu Y, Cao Q, Ren C, Ponomarenko A, DeCarli LM (2004): Model of nonalcoholic steatohepatitis. Am. J. Clin. Nutr. 79, 502-509 https://doi.org/10.1093/ajcn/79.3.502

Lotková $\mathrm{H}$, Červinková $\mathrm{Z}$, Kučera $\mathrm{O}$, Kriváková $\mathrm{P}$, Kandár $\mathrm{R}$ (2005): Protective effect of S-adenosylmethionine on cellular and mitochondria 1 membranes of rat hepatocytes against tertbutylhydroperoxide-induced injury in primary culture. Chem. Biol. Interact. 156, 13-23 https://doi.org/10.1016/j.cbi.2005.06.008

Mehal WZ, Iredale J, Friedman SL (2011): Scraping fibrosis: expressway to the core of fibrosis. Nat. Med. 17, 552-523 https://doi.org/10.1038/nm0511-552

Moravcová A, Červinková Z, Kučera O, Mezera V, Rychtrmoc D, Lotková H (2015): The effect of oleic and palmitic acid on induction of steatosis and cytotoxicity on rat hepatocytes in primary culture. Physiol. Res. 64 (Suppl. 5), S627-636

Nauck MA, Homberger E, Siegel EG, Allen RC, Eaton RP, Ebert R, Creutzfeldt W (1986): Incretin effects of increasing glucose loads in man calculated from venous insulin and C-peptide responses. J. Clin. Endocrinol. Metab. 63, 492-498 https://doi.org/10.1210/jcem-63-2-492

Nauck MA, Niederreichholz U, Ettler R, Holst JJ, Orskov C, Ritzel R, Schmiegel WH (1997): Glucagon-like peptide-1 inhibition of gastric emptying outweights its insulinotropic effects in healthy humans. Am. J. Physiol. 273, E981-988 https://doi.org/10.1152/ajpendo.1997.273.5.E981

Nauck MA, Weber I, Bach I, Richter S, Orskov C, Holst JJ, Schmiegel W (1998): Normalization of fasting glycaemia by intravenous GLP-1 ([7-36 amide] or [7-37]) in type 2 diabetic patients. Diabet. Med. 15, 937-945

https://doi.org/10.1002/(SICI)1096-9136(1998110)15:11<937::AID-DIA701>3.3.CO;2-S

Nauck MA (2008): The modulating effects of GLP-1 in type 2 diabetes. Br. J. Diabetes. Vasc. Dis. 8 (Suppl. 2), S1-S2 https://doi.org/10.1177/1474651408100521

Ohkawa H, Ohishi N, Yagi K (1979): Assay for lipid peroxides in animal tissues by thiobarbituric acid reaction. Anal. Biochem. 95, 351-358 https://doi.org/10.1016/0003-2697(79)90738-3

Ohki T, Isogawa A, Iwamoto $\mathrm{M}$, Ohsugi $\mathrm{M}$, Yoshida $\mathrm{H}$, Toda $\mathrm{N}$, Tagawa K, Omata M, Koike K (2012): The effectiveness of liraglutide in nonalcoholic fatty liver disease patients with type
2 diabetes mellitus compared to sitagliptin and pioglitazone. Scientific World Journal 2012, 496453 https://doi.org/10.1100/2012/496453

Ratziu V, Goodman Z, Sanyal A (2015): Current efforts and trends in the treatment of NASH. J. Hepatol. 62 (Suppl. 1), S65-75 https://doi.org/10.1016/j.jhep.2015.02.041

Ruhl CE, Everhart JE (2004): Epidemiology of nonalcoholic fatty liver. Clin. Liver Dis. 8, 501-519 https://doi.org/10.1016/j.cld.2004.04.008

Russel-Jones D, Gough S (2012): Recent advances in incretin-based therapies. Clin. Endocrinol. (Oxf) 77, 489-499 https://doi.org/10.1111/j.1365-2265.2012.04483.x

Samson SL, Bajaj M (2013): Potential of incretin-based therapies for non-alcoholic fatty liver disease. J. Diabetes Complications 27, 401-406 https://doi.org/10.1016/j.jdiacomp.2012.12.005

Sathyanarayana P, Jogi M, Muthupillai R, Krishnamurthy R, Samson SL, Bajaj M (2011): Effects of combined exenatide and pioglitazone therapy on hepatic fat content in type 2 diabetes. Obesity 19, 2310-2315 https://doi.org/10.1038/oby.2011.152

Sharma S, Mells JE, Fu PP, Saxena NK, Anania FA (2011): GLP-1 analogs reduce hepatocyte steatosis and improve survival by enhancing the unfolded protein response and promoting macroautophagy. PLoS One 6, e25269

https://doi.org/10.1371/journal.pone.0025269

Svegliati-Baroni G, Saccomanno S, Rychlicki C, Agostinelli L, De Minicis S, Candelaresi C, Faraci G, Pacetti D, Vivarelli M, Nicolini D, et al. (2011): Glucagon-like peptide-1 receptor activation stimulates hepatic lipid oxidation and restores hepatic signalling alteration induced by a high-fat diet in nonalcoholic steatohepatitis. Liver Int. 31, 1285-1297 https://doi.org/10.1111/j.1478-3231.2011.02462.x

Tomas E, Stanojevic V, Habener JF (2011): GLP-1-derived nonapeptide GLP-1(28-36)amide targets to mitochondria and suppresses glucose production and oxidative stress in isolated mouse hepatocytes. Regul. Pept. 167, 177-184

https://doi.org/10.1016/j.regpep.2011.01.003

Trevaskis JL, Griffin PS, Wittmer C, Neuschwander-Tetri BA, Brunt EM, Dolman CS, Erickson MR, Napora J, Parkes DG, Roth JD (2012): Glucagon-like peptide-1 receptor agonism improves metabolic, biochemical, and histopathological indices of nonalcoholic steatohepatitis in mice. Am. J. Physiol. Gastrointest. Liver Physiol. 302, G762-772 https://doi.org/10.1152/ajpgi.00476.2011

Tsuchida T, Friedman SL (2017): Mechanisms of hepatic stellate cell activation. Nat. Rev. Gastroenterol. Hepatol. 14, 397-411 https://doi.org/10.1038/nrgastro.2017.38

Tuch BE (2016): Clinical use of GLP-1 agonists and DPP4 inhibitors. Pancreatology 16, 8-9 https://doi.org/10.1016/j.pan.2015.05.465

Tushuizen ME, Bunck MC, Pouwels PJ, van Waesberghe JH, Diamant M, Heine RJ (2006): Incretin mimetics as a novel therapeutic option for hepatic steatosis. Liver Int. 26, 10151017

https://doi.org/10.1111/j.1478-3231.2006.01315.x

Valdecantos MP, Ruiz L, Pardo V, Castro-Sanchez L, GarcíaMonzón C, Lanzón B, Rupérez J, Barbas C, Naylor J, Trevaskis 
JL, et al. (2018): Differential effects of a glucagon-like peptide 1 receptor agonist in non-alcoholic fatty liver disease and in response to hepatectomy. Sci. Rep. 8, 16461 https://doi.org/10.1038/s41598-018-33949-Z

Vanni E, Bugianesi E, Kotronen A, De Minicis S, Yki-Järvinen H, Svegliati-Baroni G (2010): From the metabolic syndrome to NAFLD or vice versa? Dig. Liver Dis. 42, 320-330 https://doi.org/10.1016/j.dld.2010.01.016

Vilsbøll T, Christensen M, Junker AE, Knop FK, Gluud LL (2012) Effects of glucagon-like peptide-1 receptor agonists on weight loss: systematic review and meta-analyses of randomised controlled trials. BMJ 344, d7771

https://doi.org/10.1136/bmj.d7771
Vilsboll T, Agerso H, Krarup T, Holst JJ (2003): Similar elimination rates of glucagon-like peptide- 1 in obese type 2 diabetic patients and healthy subjects. J. Clin. Endocrinol. Metab. 88, 220-224 https://doi.org/10.1210/jc.2002-021053

Zhang Y, Yang X, Shi H, Dong L, Bai J (2011): Effect of $\alpha$-linolenic acid on endoplasmic reticulum stress-mediated apoptosis of palmitic acid lipotoxicity in primary rat hepatocytes. Lipids Health Dis. 10, 122

https://doi.org/10.1186/1476-511X-10-122

Received: September 1, 2018

Final version accepted: April 26, 2019

First published online: June 26, 2019 